antioxidantic vitamins $E$ and $A$ in blood serum have been measured.

Results: The level of concentration of MDA of recruits was $4.56 \pm 0.79 \mathrm{micromol} / 1$ (range $2.6-7.0 \mathrm{micromol} / 1$; concentration of vitamin $\mathrm{E}=21.8 \pm 0.41 \mathrm{micromol} / 1$ (range: $8-44 \mathrm{micro}-$ $\mathrm{mol} / \mathrm{l}$; and concentration of vitamin $A=2.18 \pm 0.41 \mathrm{micromol} / 1$ (range 1.3-3.3 micromol/1). Increased MDA concentration ( $\geq 5.0 \mathrm{micromol} / \mathrm{l}$ ) was found for $38.3 \%$ smokers and $27.7 \%$ non-smokers respectively $(p<0.05)$. Vitamin $\mathrm{E}$ of smokers did not differ from its concentration of non-smokers. Vitamin A level of smokers was higher than of non-smokers $(2.23 \pm 0.39$ and $2.07 \pm 0.41 \mathrm{micromol} / \mathrm{l}$ respectively, $p<0.01$ ). Morbidity among smokers and non-smokers did not differ significantly. The MDA concentration of recruits with higher morbidity ( $>3$ cold troubles) was higher $(4.68 \pm 0.85 \mathrm{micromol} / \mathrm{l})$ than of those with less morbidity $(4.44 \pm 0.97 \mathrm{micromol} / \mathrm{l})(p<0.05)$. Among persons with higher morbidity during service MDA concentration had a tendency to increase and vitamin $\mathrm{E}$ concentration tended to decrease.

Conclusion: Smoking and morbidity of recruits were associated directly with oxidative stress marker, MDA, and morbidity was adversely associated loosely with the levels of Vitamin E; an increase of the level Vitamin A in serum of smokers has been known as a biochemical response to this harmful habit among young persons.

Keywords: antioxidants; military; morbidity; smoking; soldiers; vitamins

Prebosp Disast Med 2002;17:s14.

\section{A 58 Year Follow-Up of World War II Veterans Weisaeth $L,{ }^{1}$ Kristiansen $H,{ }^{1}$ Herlofsen $P^{2}$ Vold $O,{ }^{3}$ Oeygard $K^{3}$}

1. HQ The Norwegian Armed Forces, Medical Staff, Department of Psychiatry

2. Oslo Military Surgery and Dental Clinic

3. The National Health Insurance Administration

Introduction: The paper reports preliminary findings from a study of veterans from a Norwegian infantry battalion ( $\mathrm{n}=$ $797)$, who still are alive $(n=85)$, and who fought the invading German forces in Northern-Norway during April-June 1940. The data from the combat veterans were compared with those from the soldiers from a battalion that was kept in reserve and did not experience combat. During the subsequent occupation of Norway, members of both battalions, however, experienced with their families, other war stressors, in particular the scorched earth policy of the retreating Wehrmacht during the fall and winter of 1944-1945.

The combat battalion had six weeks of continuous operations in high-mountain terrain under severe winter conditions. The battalion was part of the first allied combined operations during World War II, which ended in the successful liberation of Narvik. They were on the offensive the whole time, suffered few losses - but when the final victory was reaped, the allies had to withdraw from Norway because of the critical development on the European continent, and Norway capitulated.

Methods: The veterans underwent extensive personal physical and psychiatric examinations. The military health records from the war time and throughout their later military service as well as medical data from their civilian lives were studied.

Results and Conclusions: A response rate of $99 \%$ was obtained. The following preliminary findings will be discussed: 1) No increase in mortality was found among the combat veterans compared to non-combat veterans and civilian groups matched for age, place of birth, and living; 2) No cases that fit within the post-traumatic stress spectrum were identified in the non-combat battalion; 3) About $30 \%$ of the combat veterans suffered from partial PTSD with low rates of co-morbid disorders; 4) Few of the partial PTSD cases had suffered a diminished work capacity; and 5) No cases of late psychic sequellae or significantly delayed PTSD were identified.

Keywords: combat veterans; comorbidity; mortality; post-traumatic stress disorder (PTSD); work, capacity for

Prehosp Disast Med 2002;17:s14.

\section{Traumatic Stressors in Terrorism: Norwegian Merchant Sailors in the Arabian Gulf 1984-1988 Weiseth $L^{1,2}$ Mehlum $L^{1,2}$ Lie $T^{3}$}

1. HQ, The Norwegian Armed Forces, Medical Staff, Department of Psychiatry

2. Division of Disaster Psychiatry, University of Oslo, Oslo, Norway

3. Seamen's Medical Office, Oslo, Norway

Traumatic stressors and their aftermath were studied in 188 Norwegian merchant sailors who were exposed to terror attacks or threats of attacks while sailing through international waters in the Arab Gulf during the first Gulf War (1984-1988). Two years after the end of the war, 38 cases $(20 \%)$ of post-traumatic stress reactions were identified in the sample - of which $66 \%$ had been exposed to one or more terror attacks. A significant correlation was found between the number of attacks and also, the number of voyages into the Arab Gulf; each had a separate and independent effect.

Keywords: merchant sailors; post-traumatic stress reactions; terrorism

Prehosp Disast Med 2002;17:s15. 